\title{
RESEARCH
}

Open Access

\section{Fifteen-year trends in self-reported racism and link with health and well-being of African Canadian adolescents: a secondary data analysis}

Helen U. Okoye ${ }^{*}$ (i) and Elizabeth Saewyc

\begin{abstract}
Background: We assessed the prevalence and trends in racial discrimination among African Canadian adolescents in British Columbia. The association between racial discrimination and self-rated health, access to mental health services, substance use, suicidal thoughts and attempts, experience of extreme stress, among others were examined within the 2018 dataset.

Methods: Secondary analysis used the data collected from African Canadian adolescents $(n=2448)$ as part of the British Columbia Adolescent Health Surveys (2003-2018). We examined whether racial discrimination increased, decreased, or remained stable over time. We evaluated experiences of racial discrimination for all adolescents, and then disaggregated analyses for boys, girls, immigrant, and Canadian-born African adolescents. We used Rao-Scott's adjusted chi-square to test differences in racial discrimination and adjusted logistic regressions to test trends across survey years, widening or narrowing gaps in racial discrimination, as well as the link to health outcomes.

Results: Racial discrimination was significantly different across the survey years (Adjusted $F=4.60, p<.01$ ), with the highest percentage of adolescents reporting past year racial discrimination in 2018 (29.9\%) and the lowest percentage in 2013 (21.3\%). Girls and immigrant African Canadian adolescents were more likely to have experienced racial discrimination. However, girls and Canadian-born adolescents had the highest odds of reporting racial discrimination in 2018 compared to 2003, $A O R=1.85$, and 1.58, respectively. The findings reveal significant differences in the experiences of racial discrimination for boys and girls, as well as for immigrant and Canadian-born African adolescents. Significant differences were noted in the link between racial discrimination and self-rated health and engaging in behaviours that might expose them to health risks. The worst negative health outcomes were found for boys and immigrant African Canadian adolescents.

Conclusion: The study suggests that more than 1 in 4 African Canadian adolescents in British Columbia report racial discrimination, which is an increasing trend in recent years. Those who reported racial discrimination also had the worst adverse health outcomes. There is a need for more public health action to reduce racism, create awareness about the negative health impacts, and provide better support for African Canadian adolescents.
\end{abstract}

Keywords: Adolescents, Racial discrimination, Gender, Immigrant, Canadian-born

\footnotetext{
* Correspondence: helen.okoye@alumni.ubc.ca

University of British Columbia, School of Nursing, Vancouver, British Columbia, Canada
}

C C The Author(s). 2021 Open Access This article is licensed under a Creative Commons Attribution 4.0 International License, which permits use, sharing, adaptation, distribution and reproduction in any medium or format, as long as you give appropriate credit to the original author(s) and the source, provide a link to the Creative Commons licence, and indicate if changes were made. The images or other third party material in this article are included in the article's Creative Commons licence, unless indicated otherwise in a credit line to the material. If material is not included in the article's Creative Commons licence and your intended use is not permitted by statutory regulation or exceeds the permitted use, you will need to obtain permission directly from the copyright holder. To view a copy of this licence, visit http://creativecommons.org/licenses/by/4.0/. The Creative Commons Public Domain Dedication waiver (http://creativecommons.org/publicdomain/zero/1.0/) applies to the data made available in this article, unless otherwise stated in a credit line to the data. 


\section{Background}

Racial discrimination is a public health challenge, a social determinant of health, and a major contributor to health inequities among ethnic minority groups [19, 27, 41]. It is the unfair, negative, and prejudiced attitudes and beliefs towards population groups because of their racial identity [60]. Perceived racial discrimination has been consistently linked with stress and disparities in health and illness experiences [5, 36, 54]. For instance, psychological, physiological, and cognitive reactions to experiences of racial discrimination are precursors of mental and physical health problems among individuals who perceive such discrimination $[15,19,58]$. Furthermore, perceptions of racial/ethnic discrimination among racial minority groups is associated with general selfreported poor health, as well as socioemotional distress resulting in substances use, sexual intercourse without the use of adequate protective tools, suicidal thoughts and attempts $[33,59]$. However, available evidence indicate that Blacks report more racial discrimination compared to other ethnic minority groups [30, 60].

During adolescence, attitudes and behaviours that influence adult life are formed and become embedded in an individual $[6,54,55]$. Additionally, the developing adolescent brains are still learning to adapt and cope with the socioemotional challenges in the social environment, including experiences of racial discrimination [26]. Thus, at this stage of growth, young people become highly susceptible to the negative impact of racial discrimination as they form their cultural, ethnic, and racial identities. Such racial discrimination on African adolescents living amidst Caucasian-majority groups and other groups contribute to psychological stress, and affect their mental health and well-being [34, 60]. Studies have repeatedly indicated that exposure to racial discrimination in early years, particularly during adolescence, are significant predictors of depressive symptoms in later years among African American adolescents [3, 15, 26].

Recent systematic and meta reviews reveal that most of the studies that examine the experiences of racial discrimination among the Black population are concentrated in the United States, U.S [35, 40]. Also, many studies examine the phenomenon among the adult Black population, while adolescents' experiences of racial discrimination and the associated health outcomes have received less attention [5, 12, 45]. A large body of evidence in the U.S. has linked experiences of racial discrimination among adolescents to psychological distress, depressive symptoms, substance use, and other behaviours that might expose them to health risks $[3,5,15]$. Gender has been shown to moderate the relationship between racial discrimination and health behaviours among adolescents $[8,42]$ Not only do experiences of racial discrimination have immediate adverse health outcomes, they have been shown to predict psychological and emotional well-being later in life particularly among men and boys [3]. Studies have documented differential experiences of racial discrimination and associated health outcomes for boy and girls [3, 5, 8, 20, 44]. For example, evidence reveals that although both boys and girls experience adverse mental health outcomes of racial discrimination, these effects lead to long-term psychological deterioration in adult life for adolescent boys than girls [3]. Furthermore, a longitudinal data analysis revealed that cumulative racial discrimination predicts higher use of substances among boys in their young adulthood than for girls [8].

Besides gender differences in the relationships between racial discrimination and health outcomes, many studies have examined this link for first- and second-generation immigrants, albeit, confounding results [17, 52]. For instance, experiences of racial discrimination, and the associated poorer health outcomes are higher among first generation immigrants, [52], particularly during adolescence $[16,39]$. Even more so as acculturation and language barrier may worsen these experiences and lead to increase in experiences of stress, as shown among firstgeneration immigrant adolescents in the U.S. [48]. Additionally, the healthy immigrant effect explains the better health outcomes that have been documented among people who move from developing to developed countries $[16,25]$.. Evidence suggests that first generation immigrants are healthier than their native-born counterparts, given the selective immigration policies in the destination country. Also, the higher social support from the African community in the recipient country might explain the differential health outcomes [7, 16, 25, 52]. However, the immigration-health paradox tends to fade off with longer years in the host country [16, 47]. Given that majority of these studies are in the United states, evidence is still scant about the relationship between experiences of racial discrimination and the wellbeing of first-generation immigrant and Canadian-born African adolescents.

The Black population has only increased in British Columbia in recent years and extrapolating findings from the U.S. to Canada may be inaccurate [56]. Black Canadians represent $3.5 \%$ of Canada's population and accounts for $15.6 \%$ of the minority ethnic groups in Canada [50]. Further, British Columbia is the most culturally diverse province in Canada, and the third largest province in the country, but the province hosts a very small number of Black Canadians. The ethnic group represents $1 \%$ of the Province's population [50]. Thus making them a visible minority ethnic group in the province [50].

As the Canadian Government commits to promoting mental health and well-being across the life span and 
reducing health disparities, there is a need to investigate the experiences of racial discrimination among Black Canadian adolescents, and the changes in experiences of racial discrimination over time. A limited number of studies have investigated experiences of racial discrimination among Black Canadian adults and college students in Canada [24, 53, 56]. However, the prevalence and trends in racial discrimination among African Canadian adolescents in British Columbia have received less attention, despite relevant associations of racial discrimination with adverse health outcomes among individuals in this age group.

The current study sought to fill this critical gap in Canadian data, by assessing the prevalence and trends in racial discrimination among African Canadian adolescents in British Columbia. The study evaluated the links between racial discrimination and well-being of African Canadian adolescents. Also, experiences of racial discrimination and the link with health outcomes were assessed separately for boys, girls, first generation immigrant African adolescents and African adolescents born in Canada.

\section{Purpose of the study}

The study examined the prevalence and 15-year trends in racial discrimination, as well as the link between experiences of racial discrimination and health outcomes using data obtained from the province-wide British Columbia Adolescent Health Survey (BCAHS). The McCreary Centre Society (MCS) conducts the BCAHS every five years among a representative sample of students in Grades 7 to12. The survey includes questions about adolescents' ethnic background and experiences of discrimination related to race, ethnicity, or skin colour, in addition to other questions that address adolescents' health behaviour.

\section{Research questions}

The current study addressed four questions relating to racial discrimination among African Canadian adolescents: (1) What is the prevalence of past year racial discrimination among African Canadian Adolescents in British Columbia in the relevant survey years? (2) Was there a significant difference in experiences of racial discrimination for boys versus girls, and for immigrant versus Canadian-born African adolescents? (3) Was there a significant difference in trends (decreased, increased, or unchanged) of racial discrimination among the adolescents between 2003 and 2018? (4) Was there a link between experiences of racial discrimination and self-rated health, experience of extreme stress, access to health services, substance use, suicidal thoughts and attempts among African Canadian adolescents in British Columbia?

\section{Method}

\section{Survey design and procedure}

The BCAHS is a cross-sectional school-based survey that is conducted every five years using cluster-stratified sampling to select provincially representative students in classrooms. The survey examines risks and protective factors that influence adolescent health behaviours, including exposure to violence and discrimination as well as youth assets, family, school and community connectedness $[43,49]$. The sampling frame used for the surveys was comprised of enrolled students who were in grades 7 to 12 (ages 12 to 18 years) in public school districts in British Columbia. Samples in each year of the surveys were randomly selected from classrooms stratified by grade and health service delivery area (HSDA) across the province. Data obtained from the surveys are weighted to adjust for the complex survey design and scaled to represent the population of enrolled students. The number of participating school districts have increased steadily since the first survey in 1992, and in 2018, 58 out of the 60 school districts in the province participated in the survey [29, 43]. While the questionnaire has mostly remained the same over the years, allowing for trend analyses, some questions have been updated to reflect current social issues $[43,46]$. The paper and pencil questionnaire of 140 -items is usually administered by public health nurses and nursing students and completed anonymously by the students.

\section{Sample selection}

The last four surveys of the BCAHS from years 2003, 2008, 2013 and 2018 were used for the trend analysis because questions about ethnicity prior to 2003 did not include African Canadian adolescents. The total sample of school students who participated in the BCAHS between 2003 and 2018 was 126,994. The unweighted sample of African Canadian adolescents in the survey years under review was 2448, ranging between 439 and 808 from 2003 to 2018. The weighted, scaled sample size of African Canadians adolescents ranged from 4651 in 2003 to 5744 in 2018 , with a total of 21,834 across all 16 years. Given that the survey includes grades 7 through 12, it is possible that some adolescents might have participated in the survey twice, but since the overall sample is only about $10 \%$ of enrolled students in each sample year, it is unlikely that students have participated in the survey twice, given the few participants in any year.

\section{Inclusion and exclusion criteria}

For the current study, participants were included in the analysis if they (1) self-identified as African (2) responded to the relevant survey questions in the relevant survey years from 2003 to 2018. To ensure reliable trends, only school districts that participated in at least 
three of the four survey years (94.2\%) were included in this analysis. Also, adolescents who did not indicate their gender $(0.1 \%)$ were excluded from the analysis.

\section{Measures}

The dependent variable for this analysis was experiences of racial discrimination in the past year, based on the question, "In the past 12 months, have you been discriminated against or treated unfairly because of your race, ethnicity or skin colour?" Response options were yes or no. Several additional variables from the BCAHS were used to assess the link between racial discrimination and health and well-being of African Canadian adolescents: being sexually active or having given or received oral sex, ever smoked a cigarette, used alcohol, or other substances (e.g., cocaine, heroin, amphetamine, crystal methamphetamine, hallucinogens), as well as self-rated health, and access to mental health and emotional health services. Variables were originally coded or recoded as binary (yes or no). The socio-demographic variables included in the analysis were age, gender, and birthplace. The participant's birthplace was a dichotomous variable that measured first-generation immigrants, subsequently referred to as immigrants, or Canadianborn adolescents. Gender was measured as a binary variable (boys and girls) in the survey years prior to 2018, but 2018 included both the sex assigned at birth and a gender identity question that offered more than binary options. To provide a consistent measure of gender for reliable trends across years, gender in this analysis was based on sex assigned at birth.

\section{Data analysis}

All analyses were performed with the Complex Samples analytical procedures incorporated in IBM SPSS 26 [22]. Complex Samples procedures not only adjust for unequal probabilities of selection that are associated with clustering and stratification, but also the use of weights. The alpha criterion was set at 0.05 for all analyses. Descriptive statistics, including percentages, means and standard deviations assessed the age distribution of respondents. The SPSS Complex Samples General Linear Models assessed significant differences in age distribution of the respondents across the survey years. The prevalence of racial discrimination was evaluated for each survey year for all respondents, and then disaggregated by gender and birthplace (immigrant vs. Canadian-born African adolescents). Rao-Scott's chisquare statistic was used to test the differences in prevalence of racial discrimination across the survey years to account for the clustered data.

To determine whether there were statistically significant different trends in racial discrimination over time, logistic regression analyses were conducted to compare data for 2003, 2008, 2013 and 2018 survey years, with age as a covariate to control for potential differences in sample distributions across years. The logistic regression model assessed whether racial discrimination had increased, decreased, or remained stable in 2008, 2013 and 2018, compared to 2003. Age-adjusted odds ratios (AOR) were used to interpret the result of the analyses, where significant AOR greater than or less than 1 shows increasing or decreasing trends, respectively.

Furthermore, for any observed differences of experiences of racial discrimination between boys and girls, and immigrant versus Canadian-born African Canadian adolescents, we tested whether such differences widened, narrowed, or remained unchanged between groups across the given years. We used a recent approach for examining trends and identifying trends in the gaps between groups developed by Homma, Saewyc, and Zumbo [21]. Interaction terms by gender and survey year were included in the regressions, with girls and 2003 survey year as the referent groups, as well as interactions by birthplace and survey year, with Canadianborn adolescents and 2003 survey year as referent categories. The interaction term is a ratio of odds ratios, which compares the AOR of racial discrimination by adolescent's gender or birthplace for the specified year (e.g., 2018) to the AOR of racial discrimination by gender or birthplace for the referent year (e.g., 2003). Significant interaction odds would indicate that change over time was different for boys and girls, or for Canadian-born versus immigrant African adolescents. This shows that gaps in experiences of racial discrimination for boys, girls, immigrant, or Canadian-born adolescents may be narrowing or widening. The interpretation of the odds ration (OR), and interaction terms are shown in Table 1 . The main OR and interaction OR were examined to determine whether the gap widened or narrowed, as suggested by Homma et al. [21]. We controlled for age of respondents in all logistic regression models.

Finally, using the 2018 data only, bivariate logistic regressions were used to assess the link between experiences of racial discrimination and self-rated health, experiences of stress, access to health services, as well ever smoked a cigarette or used alcohol, among others. The results were interpreted with the adjusted odds ratios and confidence intervals.

Adapted with permission from Homma et al. [21].

\section{Results}

\section{Socio-demographic profile}

Descriptive statistics show that most of the African Canadian adolescents were 18 years old or younger (98.6\%). In these survey years, more than half of the population of African Canadian adolescents were boys (52.1 to 
Table 1 Interpretation of Odds Ratio for Gap Analysis

\begin{tabular}{llll}
\hline & Original ORs & ORs for interaction terms & Racial discrimination \\
\hline Year 2008, 2013 or 2018 & $>1$ & $>1$ & Widening \\
Year 2008, 2013 or 2018 & & $<1$ & Narrowing \\
Year 2003 (reference) & $<1$ & $<1$ & Narrowing \\
Year 2008, 2013, or 2018 & & $>1$ & Narrowing \\
Year 2008, 2013, or 2018 & & $<1$ & Widening \\
Year 2003 (reference) & $<1$ & Widening
\end{tabular}

Note. Main effect ORs for a specified year and referent year $>1$, interaction ORs $>1=$ Gap widening. Interaction ORs $<1=$ Gap narrowing. Main effect ORs for a specified year and referent year $<1$, and Interaction ORs $>1=$ Gap narrowing. Interaction ORs $<1=$ Gap widening. ${ }^{a}$ ORs; Odds ratios from logistic regression models that examined racial discrimination within 2003, 2008, 2013, 2018 survey years

52.5\%). All the African Canadian adolescents identified as either boys or girls in 2003, 2008, and 2013. In 2018, almost all the African Canadian adolescents (99.9\%) indicated their gender as the sex assigned at birth. Disaggregated data for immigrant and Canadian-born African adolescents indicate that a greater percentage (69.5\%) were born in Canada.

The mean age of the weighted sample of all adolescents was 15.1 years, and there was no significant difference in the age distribution of all African Canadian adolescents in $2008(p=.25), 2013(p=.28$, and 2018 $(p=.06)$ compared to 2003. However, boys were significantly younger in 2013 compared to $2003(p<.05)$. On the other hand, adolescent girls were significantly younger in 2008 and 2018 compared to $2003(\mathrm{p}<.05)$. While there was no significant age difference in the mean age of Canadian-born adolescents in $2008(p=.16), 2013$ $(p=.22)$ and $(2018, p=.56)$ compared to 2003. The immigrant African Canadian adolescents were significantly younger in other years compared to $2003(p<.01)$. Further, majority of the African Canadian adolescents (86.7\%) had lived in Canada for six years or longer. Only a very small percentage (4.6\%) of the adolescents lived in Canada for less than two years. From 2003 to 2018, most of the adolescents (93.2 to 92.3\%) lived with their parents, and another 6.1 to $5.2 \%$ lived with adults who were not their parents.

\section{Prevalence of racial discrimination by gender, and for immigrant and Canadian-born adolescents}

Figure 1 depicts the unadjusted 15-year prevalence estimates of racial discrimination for all African Canadian adolescents, and then disaggregated by gender. The results reveal that racial discrimination was highest in 2018 and lowest in 2013. These experiences remained higher for adolescent girls compared to boys in all the years, were lower for both groups in 2013 compared to 2018, but increased exponentially for girls in 2018. The unadjusted 15-year prevalence of racial discrimination disaggregated for immigrant and Canadian-born adolescents is shown in Fig. 2. Immigrant African Canadian adolescents reported higher prevalence of racial discrimination in 2003, 2013 and 2018 compared to Canadianborn adolescents. These findings were further examined controlling for age in logistic regression models to determine significant changes over the 15 -year period.

\section{Logistic regression analyses of racial discrimination across survey years \\ Differences for boys, girls, immigrant, and Canadian-born African Canadian adolescents}

The age-adjusted logistic regression analyses (Table 2) reveal that there were no significant differences in racial discrimination by gender in 2003, 2008 or 2013. However, in 2018 , girls were $59 \%$ more likely than boys to have reported racial discrimination $(p<.01)$. Compared to Canadian-born adolescents, immigrant African Canadian adolescents were $113 \%$ as likely to have reported racial discrimination in $2003(p<.05)$ and $65 \%$ more likely to have reported racial discrimination in $2013(p<.05)$. Racial discrimination did not significantly differ between Canadian- and immigrants adolescents in either 2008 or 2018.

\section{Trends in racial discrimination}

The trend analyses (Table 3 ) indicate that the odds of racial discrimination were lowest in 2013 for boys, girls, immigrant, and Canadian-born adolescents. Experiences of racial discrimination were significantly lower for boys in 2013 compared to 2003 and 2008. Adolescent girls had higher odds of reporting racial discrimination in 2018 compared to the previous years. For instance, girls were 85 and $60 \%$ more likely to have experienced racial discrimination in 2018 compared to the experiences of racial discrimination in 2003 and 2008, respectively. Also, adolescent girls were $137 \%$ more likely to have reported racial discrimination in 2018 compared to 2013. On the other hand, in 2018, Canadian-born adolescents were 58 and $95 \%$ more likely to have reported racial discrimination compared to 2003 and 2013, respectively, while immigrant African adolescents had significantly declining prevalence between 2003 and 2013. Also, the increase in prevalence of racial discrimination in 2018 


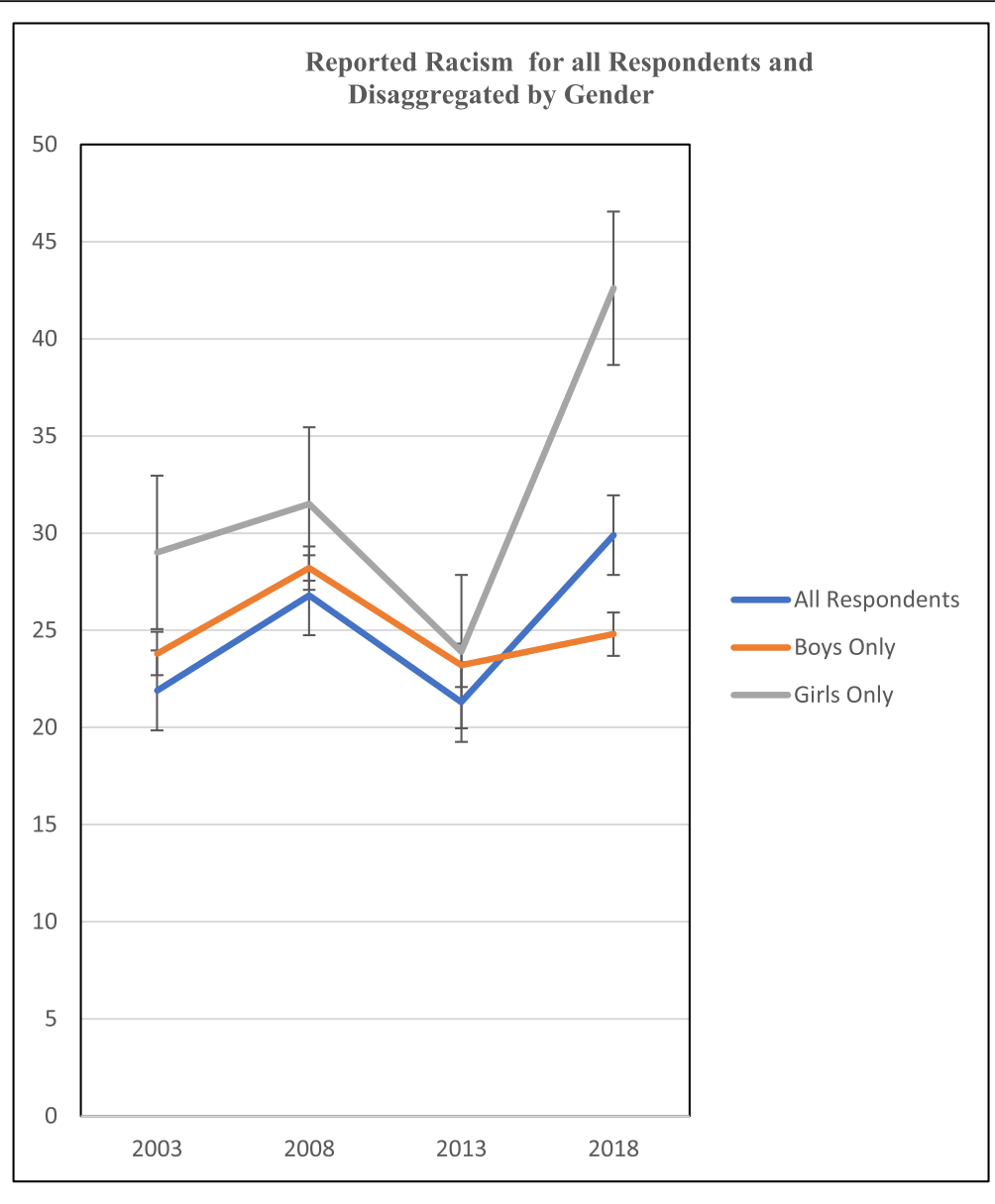

${ }^{\mathrm{b}}$ error bars represent standard errors

Fig. 1 Reported Racism for all Respondents and Disaggregated by Gender

was not significantly different compared to the other years for immigrant adolescents.

\section{Gaps in racial discrimination by adolescents' gender and birthplace}

The gap analysis shown in Table 4 reveal that the gap in experiences of racial discrimination between boys and girls remained unchanged in $2008(p=0.60)$ and 2013 $(p=0.41)$ compared to 2003 , but significantly narrowed in 2018 compared to $2003(p<.01)$. However, adolescent girls still had the highest odds of reporting racial discrimination in 2018 compared to other years $(p<.01)$. The gap between immigrant- and Canadian-born adolescents in experiences of racial discrimination narrowed in 2008 ( $\mathrm{p}<.01)$ compared to 2003 but remained unchanged in $2013(p=0.33)$, and $2018(p=0.06)$.

\section{Racial discrimination and link with adolescents' health and wellbeing}

The link between racial discrimination and health and wellbeing of African Canadian adolescents were assessed using the 2018 dataset. Bivariate logistic regression models were used to assess the association of racial discrimination with self-rated health, experiences of stress, access to health services, substance use, sexual intercourse without the use of adequate protective tools, among others. The findings reveal that self-rated health was poorer for adolescents who reported racial discrimination, and they had a higher likelihood of engaging in behaviours that could put them at risk for adverse health outcomes compared with those who did not report racial discrimination (Table 5). These adolescents who reported racial discrimination were 48 and $46 \%$ more likely to have ever smoked a cigarette or used any substances (e.g., cocaine, heroin, e.t.c.) respectively, compared to those did not report experiencing racial discrimination. Additionally, adolescents who experienced racial discrimination were $97 \%$ more likely to have considered suicide and more than two times as likely to have attempted suicide $(p<0.5)$ than adolescents who did not report experiencing racial discrimination. These adolescents also significantly reported extreme stress 


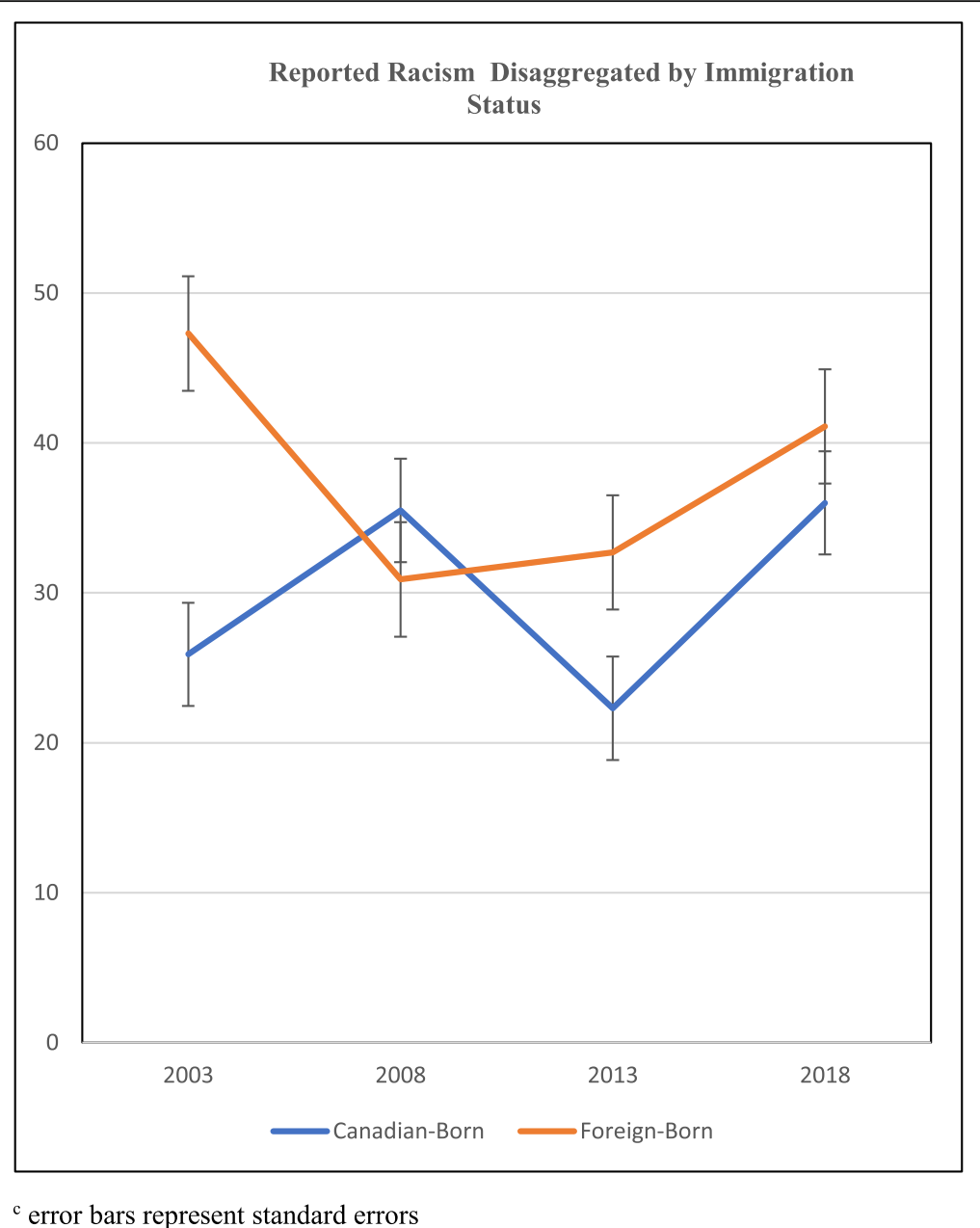

Fig. 2 Reported Racism Disaggregated by Immigration Status

and not receiving needed emotional and mental health services, 68 and 121\% respectively.

Regression Analysis of Racial Discrimination and Health and Well-being Disaggregated by Gender

The results show that experiences of racial discrimination were significantly associated with engagement in behaviours that expose young people to health risks for both boys and girls, but adolescent boys had the worst health outcomes (Table 6). African Canadian boys who experienced racial discrimination were significantly more likely to have ever smoked a cigarette $(p<.05)$, and used other substances, such as cocaine, and heroine $(p<.01)$. The boys also significantly reported general poor health, extreme stress, suicidal attempt, and were more likely to be sexually experienced, e.g., having had sex, given, or received oral sex $(p<.05)$, compared to adolescent girls. While adolescent girls who experienced racial discrimination were two times as likely to have considered suicide compared to those who did not report racial discrimination, boys were three times more likely to have

Table 2 Racial Discrimination Stratified by Gender, and for Immigrant and Canadian-born Adolescents

\begin{tabular}{llllll}
\hline & All Respondents** & Boys Only* & Girls Only** & Boys (vs Girls) & Immigrant (vs Canadian-born) $^{*}$ \\
\hline \multirow{2}{*}{2003} & AOR $(95 \% \mathrm{Cl})$ & AOR $(95 \% \mathrm{Cl})$ & $\mathrm{AOR}(95 \% \mathrm{Cl})$ & $\mathrm{AOR}(95 \% \mathrm{Cl})$ & $\mathrm{AOR}(95 \% \mathrm{Cl})$ \\
2008 & $21.9(18.0,26.4)$ & $23.8(19.1,29.2)$ & $29.0(21.2,38.2)$ & $1.50(.91,2.48)$ & $2.13(1.13,4.03)^{*}$ \\
2013 & $26.8(23.8,30.2)$ & $28.2(24.4,32.4)$ & $31.5(25.6,38.2)$ & $1.27(.85,1.90)$ & $0.81(0.51,1.28)$ \\
2018 & $21.3(18.4,24.5)$ & $23.2(19.5,27.3)$ & $23.9(18.9,29.8)$ & $1.15(.79,1.67)$ & $1.65(1.08,2.50)^{*}$ \\
\hline
\end{tabular}

${ }^{*} p<.05,{ }^{* *} p<.01,{ }^{* * *} p<.001, \mathrm{AOR}=$ Age adjusted odds ratio. ${ }^{*}$ Referent group: Girls, Canadian-born adolescents 
Table 3 Trends in Racial Discrimination by Year disaggregated by Gender and Birthplace

\begin{tabular}{|c|c|c|c|c|}
\hline & Boys Only & Girls Only & Canada-born & Immigrants \\
\hline & AOR $(95 \% \mathrm{Cl})$ & AOR $(95 \% \mathrm{Cl})$ & AOR $(95 \% \mathrm{Cl})$ & AOR $(95 \% \mathrm{Cl})$ \\
\hline \multicolumn{5}{|l|}{ Model 1} \\
\hline 2008 (vs 2003) $^{a}$ & $0.98(0.62,1.56)$ & $1.15(0.70,1.91)$ & $1.55(1.02,2.36) *$ & $0.53(0.30,0.94)$ * \\
\hline 2013 (vs 2003) $^{a}$ & $0.60(0.38,0.96) *$ & $0.78(0.47,1.29)$ & $0.81(0.53,1.25)$ & $0.57(0.33,0.99)$ * \\
\hline 2018 (vs 2003) $^{a}$ & $0.79(0.50,1.24)$ & $1.85(1.17,2.94) * *$ & $1.58(1.07,2.35) *$ & $0.83(0.49,1.41)$ \\
\hline \multicolumn{5}{|l|}{ Model 2} \\
\hline 2013 (vs 2008) $^{b}$ & $0.61(0.43,0.87) * *$ & $0.68(0.44,1.03)$ & $0.52(0.37,0.74) * * *$ & $1.08(0.66,1.76)$ \\
\hline 2018 (vs 2008) $^{b}$ & $0.80(0.57,1.12)$ & $1.60(1.12,2.30) * *$ & $1.02(0.76,1.38)$ & $1.56(0.97,2.49)$ \\
\hline \multicolumn{5}{|l|}{ Model 3} \\
\hline 2018 (vs 2013) $^{c}$ & $1.31(0.93,1.85)$ & $2.37(1.64,3.44) * * *$ & $1.95(1.43,2.65)^{* * *}$ & $1.45(0.93,2.26)$ \\
\hline
\end{tabular}

attempted suicide $(p<.05)$. Regardless of gender, African Canadian adolescents who experienced racial discrimination were significantly less likely to have received emotional and mental health services $(p<.01)$, compared to those who did not report experiencing racial discrimination.

Racial Discrimination and Association with Health and Well-Being Disaggregated by Birthplace

The differences in the experiences of racial discrimination and the link with adolescents' health and wellbeing are shown in Table 7 . The results indicate that

Table 4 Year by Gender and Year by Birthplace Interactions Effects on Experiences of Racial Discrimination

\begin{tabular}{|c|c|}
\hline & AOR $(95 \% \mathrm{Cl})$ \\
\hline \multicolumn{2}{|l|}{ Model 1} \\
\hline \multicolumn{2}{|l|}{ Gender Gap } \\
\hline Boys & $1.49(0.91,2.45)$ \\
\hline 2008 & $1.27(0.85,1.89)$ \\
\hline 2013 & $1.15(0.79,1.67)$ \\
\hline 2018 & $1.87(1.18,2.97)^{* *}$ \\
\hline Boys $\times 2008$ (vs 2003) ${ }^{a}$ & $0.84(0.45,1.59)$ \\
\hline Boys $\times 2013$ (vs 2003) $^{a}$ & $0.77(0.42,1.43)$ \\
\hline Boys $\times 2018$ (vs 2003) ${ }^{a}$ & $0.42(0.23, .76) * *$ \\
\hline \multicolumn{2}{|l|}{ Model 2} \\
\hline \multicolumn{2}{|l|}{ Birthplace } \\
\hline Immigrant & $2.34(1.31,4.17)^{* *}$ \\
\hline 2008 & $1.55(1.01,2.36)^{*}$ \\
\hline 2013 & $0.81(.53,1.25)$ \\
\hline 2018 & $1.58(1.07,2.36) *$ \\
\hline Immigrant × $2008\left(\right.$ vs 2003) ${ }^{a}$ & $0.34(0.17,0.72)^{* *}$ \\
\hline Immigrant × 2013 (vs 2003) $^{a}$ & $0.70(0.35,1.43)$ \\
\hline Immigrant × $2018\left(\right.$ vs 2003) ${ }^{a}$ & $0.52(0.26,1.03)$ \\
\hline
\end{tabular}

Canadian-born African adolescents who reported racial discrimination were significantly more likely to report poor health outcomes. For instance, $61 \%$ reported general poor health, $91 \%$ reported extreme stress while $97 \%$ said that they did not receive needed emotional and mental health. However, immigrant African Canadian adolescents who experienced racial discrimination by far engaged in coping strategies that may affect health and well-being. They were more than two times as likely to have ever smoked cigarette or used substances $(p<.01)$, five times more likely to have considered suicide $(p<.001)$, four times more likely to have attempted suicide $(p<.05)$, and more than 3 times as likely to report not receiving needed emotional and mental health services $(p<.001)$.

\section{Discussion}

This study examined fifteen-year trends in perceived racial discrimination and the link with health and wellbeing among African Canadian adolescents in British Columbia Canada. The findings of the study are consistent with reports of racial discrimination among adolescents and other minority ethnic groups, including African American adolescents in the United States and elsewhere $[5,19,35]$. The findings reveal an increasing

Table 5 Logistic Regression of Racial Discrimination, Health Behaviours and Access to Health Services

\begin{tabular}{ll}
\hline & AOR $(95 \% \mathrm{CI})$ \\
\hline Cigarette smoking & $1.48(1.03,2.11)^{*}$ \\
Substance use (e.g., heroin, cocaine) & $1.46(1.02,2.09)$ \\
Suicidal thoughts & $1.97(1.32,2.94)^{* *}$ \\
Suicidal attempt & $2.05(1.10,3.83)^{*}$ \\
Good Health & $0.62(0.43,0.89)^{* *}$ \\
Extreme Stress & $1.68(1.08,2.61)^{*}$ \\
Did not receive mental health services & $2.21(1.54,3.17)^{* * *}$ \\
\hline
\end{tabular}

${ }^{*} p<.05,{ }^{* *} p<.01,{ }^{* * *} p<.001$ 
Table 6 Regression Analyses of Racial Discrimination and Health and Well-Being Disaggregated by Gender

\begin{tabular}{lll}
\hline & \multicolumn{1}{l}{ Racial Discrimination } \\
\cline { 2 - 3 } & Boys AOR (95\% Cl) & Girls AOR (95\% Cl) \\
\hline Ever had a drink of alcohol & $1.38(0.88,2.16)$ & $1.14(0.72,1.82)$ \\
Cigarette smoking & $1.73(1.07,2.79)^{*}$ & $1.26(0.74,2.15)$ \\
Substance use (e.g., heroin, cocaine) & $2.15(1.37,3.37)^{* *}$ & $0.96(0.56,1.64)$ \\
Sexually experienced (Given or received oral sex and/or ever had sex) & $1.65(1.03,2.64)^{*}$ & $1.000(.60,1.66)$ \\
Good/Excellent & $0.50(0.29,0.88)^{*}$ & $0.77(0.48,1.22)$ \\
Extreme Stress & $2.52(1.21,5.26)^{*}$ & $1.24(0.73,2.08)$ \\
Have considered suicide & $1.53(0.83,2.83)$ & $2.01(1.20,3.34) * *$ \\
Attempted suicide & $2.94(1.09,7.91)^{*}$ & $1.61(0.72,3.60)$ \\
Did not receive emotional and mental health services & $2.24(1.13,4.42) *$ & $1.93(1.24,3.01) * *$ \\
\hline
\end{tabular}

${ }^{*} p<.05,{ }^{* *} p<.01$

trend in racial discrimination in 2018 after declines between 2003 and 2013, which is troubling, and may be connected with the political changes and the increased visibility of White supremacy and anti-immigrant sentiments in North America [1].

The gender differences in experiences of racial discrimination found in this study are similar to other studies in the U.S. which found that experiences of racial discrimination are different for African American boys and girls [3]. African Canadian adolescent girls reported greater prevalence of racial discrimination than boys in this study, which might be explained by girls demonstrating an awareness of the lower social status of women, hence might develop more sensitivity to discriminatory treatment [9]. In contrast to our findings, other studies found higher levels of racial discrimination among African American boys [10, 23]. However, Cogburn, Chavous, \& Griffin [11] found no gender differences in racial discrimination, but boys reported more gender-based discrimination. The findings of this study suggest that, in different locations, racial discrimination might intersect with other forms of discrimination, such as sexism.

Our results also show that racial discrimination was reported by both immigrant and Canadian-born African adolescents, but immigrant adolescents reported higher levels of racial discrimination for most years. Experiences of racial discrimination by immigrant adolescents corroborates other studies that have documented a higher level of racial discrimination experiences among immigrant minority groups [19]. Canadian-born adolescents may be better acculturated than the immigrant African adolescents, which explains the differences in racial discrimination between immigrant and Canadianborn African adolescents [4, 14]. On the other hand, lower proficiency in the English Language and darker skin colour were associated with higher levels of racial discrimination [2]. However, the increase in racial discrimination in the past five years, even for Canadianborn adolescents, suggests a growing trend in overt racism, considering the racial sentiments in recent years across Europe and North America. For instance, researchers have documented the adverse effects of antiimmigration policies on the health and well-being of immigrants and refugees in the United States $[1,37]$.

Our study, not surprisingly, corroborated that racial discrimination is also associated with several adverse health outcomes among African Canadian adolescents. Those who experienced racial discrimination had a

Table 7 Logistic Regression of Racial Discrimination and Health Outcomes Stratified by Birthplace

\begin{tabular}{|c|c|c|}
\hline & \multicolumn{2}{|c|}{ Racial Discrimination } \\
\hline & $\begin{array}{l}\text { Canadian-Born } \\
\text { AOR }(95 \% \mathrm{Cl})\end{array}$ & $\begin{array}{l}\text { Immigrants } \\
\text { AOR }(95 \% \mathrm{Cl})\end{array}$ \\
\hline Cigarette smoking & $1.02(0.63,1.67)$ & $2.73(1.51,4.95) * *$ \\
\hline Substance use (e.g., heroin, cocaine) & $1.08(0.70,1.68)$ & $2.55(1.37,4.75]) * *$ \\
\hline Good health & $0.62(0.40,0.95) *$ & $0.59(0.32,1.09)$ \\
\hline Extreme Stress & $1.91(1.21,3.28) * *$ & $1.07(0.43,2.66)$ \\
\hline Considered suicide & $1.54(0.98,2.42)$ & $4.66(2.26,9.58) * * *$ \\
\hline Attempted Suicide & $1.64(.80,3.36)$ & $3.94(1.15,13.55) *$ \\
\hline Did not receive mental health services & $1.97(1.30,3.01) * *$ & $3.60(1.80,7.20) * * *$ \\
\hline
\end{tabular}

${ }^{*} p<.05,{ }^{* *} p<.01,{ }^{* * *} p<.001$ 
higher likelihood of reporting poorer health, psychoemotional health issues, not receiving needed emotional and mental health support. These adolescents also engaged in behaviours that can negatively affect their health and well-being compared to those who did not report racial discrimination. These results match the findings of other studies that have documented that experiences of racial discrimination among adolescents are associated with depressive and internalizing symptoms, externalizing behaviours, condom less sex, and having had multiple sexual partners $[5,12,35,36,45,51]$. Hence, there is a need to address not only interpersonal racism, but also all forms of systemic racism and barriers that continue to jeopardize the health and well-being of Black Canadian adolescents, and other racialized groups in Canada [18, 38]. Governmental and nongovernmental actions are needed to promote antiracist laws, regulations, and policies as well as attitudinal change at multiple levels of the society that will reduce the social and health inequities experienced by Black Canadian adolescents.

Furthermore, the greater use of substances among those who reported racial discrimination, necessitates that approaches for reducing harms that are associated with drug use consider the social circumstances of people who use drugs. A health equity lens will illuminate the understanding about the broader societal factors that are the major drivers of drug use among young people [32, 57]. This approach is more likely to inform interventions that address the social conditions of African Canadian adolescents' daily lives, including experiences of racial discrimination. Also, the findings reveal that adverse health outcomes related to the experiences of racial discrimination were different for boys, girls, immigrant, and Canadian-born African adolescents. Boys in this study experienced greater mental health issues and poorer emotional well-being. This finding is consistent with other studies that have shown that Black males experience greater socioemotional disturbance related to racial discrimination, which also predicts poorer health outcomes in adulthood [3, 5, 59].

Although Canadian-born adolescents reported poor health outcomes, immigrant African adolescents had worse health outcomes, which corroborates poorer health outcomes for immigrants that have been documented in previous studies [52]. Given the selective immigration policies, community support for new immigrants, the healthy immigrant effect has been shown to be protective for most immigrant population. However, the better health among immigrants compared to the larger population tend to wane with longer years of living in the host country [16, 47]. This evidence was supported by the findings of the current study, as most of the African adolescents have lived in Canada for more than six years. Hence, it is not surprising that immigrant African adolescents reported the worst health outcomes.

Furthermore, African Canadians who experienced racial discrimination were less likely to receive mental and emotional health services compared to those who did not report racial discrimination. This finding is consistent with other studies that have found poor health seeking behaviour among individuals with emotional problems, particularly racial and ethnic minorities [13, 61]. Although racial socialization and parental support improve coping and emotional well-being, evidence indicate that many adolescents who experience racial discrimination may not receive the emotional support from their families to deal with the negative mental health issues associated with racial discrimination [31, 42].

The study has some limitations that are worthy to note. As with all secondary analysis, the study was limited to the variables that are available in the data. Also, the survey asked only a single question about racial discrimination, and it is possible that students may have had different perceptions of what counts as racial discrimination. Also, experiences of racial discrimination could be normalized in the everyday life of the adolescents, which may affect reporting of those experiences. Additionally, the survey that was used for the analysis asked a question that required adolescents to identify racial and ethnic background as African. Consequently, the analysis did not evaluate the cultural diversity of Blacks, and the socially constructed identities and racial ethnic categories that might influence experiences of racial discrimination [28]. Hence, intergroup differences in experiences of racial discrimination and link with the health and well-being of African adolescents is a potential area for future study. Furthermore, the survey does not differentiate the contexts where racial discrimination was experienced, nor did the survey ask how often the students experienced discrimination, and from whom (e.g., peers, adults, people known or strangers). More detailed documentation of the frequency, type and context of discrimination would help in developing targeted interventions to prevent or reduce experiences of racial discrimination and the health outcomes. These areas are worth exploring in future studies.

Also, other characteristics that were not measured in the population dataset may influence experiences of racial discrimination, or health behaviours. For example, personality traits, racial socialization, and parental support may affect self concept and self esteem in the adolescents. This might increase or reduce racial discrimination and negative health outcomes. Additionally, socio-economic status of the family might play a role in mitigating or worsening experiences of racial discrimination. Thus, studies are needed to examine individual and family level risk and protective factors that 
may worsen or mitigate reporting of racial discrimination. Furthermore, gender was measured as a binary variable, which did not address the intersectional experiences of gender diverse and non-conforming adolescents, who experience enhanced racial discrimination and health inequities. Considering that as early as age 10 , children are aware and recognize ethnic and skin colour differences, as well as overt and covert actions that are discriminatory, we recommend assessment of experiences of racial discrimination among older children.

Despite these limitations, the strength of the study lies in the use of a population-based survey to provide important insights about the experiences of racial discrimination among African Canadian adolescents in British Columbia. Additionally, the study reveals the differential experiences of racial discrimination by boys, girls, immigrants, and African adolescents who were born in Canada. The link between experiences of racial discrimination and the health and well-being of African Canadian adolescents are useful for providing targeted as well as gender-specific interventions to mitigate the negative health outcomes of experiencing racial discrimination.

\section{Conclusion}

The increasing trends in racial discrimination and the associated adverse health outcomes found in this study are likely to contribute to widening health inequalities for African Canadian adolescents. Health professionals and social workers are well positioned to work with adolescents, families, and communities to create awareness about racial discrimination and the associated health outcomes, provide direct care to adolescents who experience racial discrimination and link them with relevant resources to cope with the negative effects of racial discrimination. These professionals and other relevant stakeholders can play a significant advocacy role informing public health policy about racial discrimination, collaborating with schools, governmental and nongovernmental agencies in reducing racial discrimination and the related health issues.

\section{Abbreviations}

HSDA: Health Service Delivery Area; BCAHS: British Columbia Adolescent Health Survey; BC: British Columbia; AOR: Age-Adjusted Odds Ratio; OR: Odds Ratio; MCS: McCreary Centre Society

\section{Acknowledgements}

The authors would like to thank the McCreary Centre Society (http://www. mcs.bc.ca) for granting them access to the 2003, 2008, 2013 and 2018 datasets of the British Columbia Adolescent Health Survey.

\section{Authors' contributions}

All authors contributed to the conception and design of the study. Data analysis was performed by $\mathrm{HO}$, who also wrote the first draft of the manuscript. ES, a co-Principal Investigator of the BCAHS, guided the analysis, and revised the manuscript for content. Both authors read and approved the final manuscript.

\section{Authors' information}

$\mathrm{HO}$ is a doctoral student at the University of British Columbia School of Nursing, Vancouver British Columbia, Canada.

ES, Professor and Director of the University of British Columbia School of Nursing in Vancouver, also leads the Stigma and Resilience Among Vulnerable Youth Centre, comprised of international and multidisciplinary research teams. For over 25 years, her research has focused on how stigma and violence influence adolescents' health and coping, and protective factors that foster resilience and health equity among young people globally.

\section{Funding}

This study was funded by an internal research fund of the University of British Columbia School of Nursing.

\section{Availability of data and materials}

The datasets used in this study were used with permission from the McCreary Centre Society. Restrictions apply to the access of these data, which are not publicly available. Please contact the McCreary Centre Society for potential access to the data.

\section{Declarations}

\section{Ethics approval and consent to participate}

The University of British Columbia gave ethical approval to carry out the $\mathrm{BCAHS}$, and administrative permission was obtained from participating school districts. Consent procedure to participate in the BCAHS has two approaches, determined by the school district, either signed parental consent and student assent, or parental notification about the study and students' consent to participate. A growing number of school districts have opted for parental notification and student consent. For instance, out of the 58 school districts that participated in the 2018 survey, 51 school districts required parental notification and student consent to participate in the survey, while only 6 school districts required signed parental consent. One school district required different consent and notification procedures depending on the age of the student $[29,43]$.

\section{Consent for publication}

Not applicable.

\section{Competing interests}

The authors declare that they do not have any conflict of interest, financial and otherwise.

Received: 9 December 2020 Accepted: 12 April 2021

Published online: 26 April 2021

\section{References}

1. Almeida J, Biello KB, Pedraza F, Wintner S, Viruell-Fuentes E. The association between anti-immigrant policies and perceived discrimination among Latinos in the US: a multilevel analysis. SSM Population Health. 2016; 2(November):897-903. https://doi.org/10.1016/j.ssmph.2016.11.003.

2. Assari $S$, Caldwell C. Darker skin tone increases perceived discrimination among male but not female Caribbean black youth. Children. 2017;4(12): 107. https://doi.org/10.3390/children4120107.

3. Assari S, Moazen-Zadeh E, Caldwell CH, Zimmerman MA. Racial discrimination during adolescence predicts mental health deterioration in adulthood: gender differences among blacks. Front Public Health. 2017; 5(May):1-10. https://doi.org/10.3389/fpubh.2017.00104.

4. Benner AD, Wang Y. Racial/ethnic discrimination and adolescents' wellbeing: the role of cross-ethnic friendships and friends' experiences of discrimination. Child Dev. 2017:88(2):493-504. https://doi.org/10.1111/ cdev.12606.

5. Benner AD, Wang Y, Shen Y, Boyle AE, Polk R, Cheng Y-P. Racial/ethnic discrimination and well being during adolescence: a meta-analytic review. Am Psychol. 2018;73(7):855-83. https://doi.org/10.1037/amp0000204.

6. Blakemore S-J, Mills KL. Is adolescence a sensitive period for sociocultural processing? Annu Rev Psychol. 2014;65(1):187-207. https://doi.org/10.1146/a nnurev-psych-010213-115202.

7. Blue L, Fenelon A. Explaining low mortality among US immigrants relative to native-born Americans: the role of smoking. Int J Epidemiol. 2011;40(3): 786-93. https://doi.org/10.1093/ije/dyr011. 
8. Brodish AB, Cogburn CD, Fuller-Rowell TE, Peck S, Malanchuk O, Eccles JS. Perceived racial discrimination as a predictor of health behaviors: the moderating role of gender. Race Soc Probl. 2011;3(3):160-9. https://doi. org/10.1007/s12552-011-9050-6.

9. Brown CS, Bigler RS, Chu H. An experimental study of the correlates and consequences of perceiving oneself to be the target of gender discrimination. J Exp Child Psychol. 2010;107(2):100-17. https://doi.org/10.1 016/j.jecp.2010.04.010.

10. Butler-Barnes ST, Richardson BL, Chavous TM, Zhu J. The importance of racial socialization: school-based racial discrimination and racial adentity among African American adolescent boys and girls. J Res Adolesc. 2019; 29(2):432-48. https://doi.org/10.1111/jora.12383.

11. Cogburn CD, Chavous TM, Griffin TM. School-based racial and gender discrimination among African American adolescents: exploring gender variation in frequency and implications for adjustment. Race Soc Probl. 2011;3(1):25-37. https://doi.org/10.1007/s12552-011-9040-8.

12. Crengle $\mathrm{S}$, Robinson E, Ameratunga S, Clark T, Raphael D. Ethnic discrimination prevalence and associations with health outcomes: data from a nationally representative cross-sectional survey of secondary school students in New Zealand. BMC Public Health. 2012;12(1):45. https://doi.org/1 0.1186/1471-2458-12-45.

13. Derr AS. Mental health service use among immigrants in the united States: A systematic review. Psychiatric Services. American Psychiatric Association. Mental Health Service Use Among Immigrants in the United States: A Systematic Review; 2016. https://doi.org/10.1176/appi.ps.201500004.

14. Duru E, Poyrazli S. Perceived discrimination, social connectedness, and other predictors of adjustment difficulties among Turkish international students. Int J Psychol. 2011;46(6):446-54. https://doi.org/10.1080/00207594.201 1.585158.

15. English D, Lambert SF, Lalongo NS. Longitudinal associations between racial discrimination and depressive symptoms in African American adolescents. Dev Psychol. 2014;50(4):1190-6. https://doi.org/10.1037/a0034703.

16. Filion N, Fenelon A, Boudreaux M. Immigration, citizenship, and the mental health of adolescents. PLoS One. 2018;13(5):1-12. https://doi.org/10.1371/ journal.pone.0196859.

17. Giuliani C, Tagliabue S, Regalia C. Psychological well-being, multiple identities, and discrimination among first and second generation immigrant muslims. Eur J Psychol. 2018;14(1):66-87. https://doi.org/10.5964/ejop.v14 i1.1434.

18. Government of Canada. (2020). Social determinants and inequities in health for Black Canadians: A snapshot. Retrieved from https://www.canada.ca/en/ public-health/services/health-promotion/population-health/whatdetermines-health/social-determinants-inequities-black-canadians-snapshot. html

19. Harris RB, Stanley J, Cormack DM. Racism and health in New Zealand: prevalence over time and associations between recent experience of racism and health and wellbeing measures using national survey data. PLoS One. 2018;13(5):1-22. https://doi.org/10.1371/journal.pone.0196476.

20. Himmelstein MS, Young DM, Sanchez DT, Jackson JS. Vigilance in the discrimination-stress model for black Americans. Psychol Health. 2015;30(3): 253-67. https://doi.org/10.1080/08870446.2014.966104.

21. Homma Y, Saewyc E, Zumbo BD. Is it getting better? An analytical method to test trends in health disparities, with tobacco use among sexual minority vs. heterosexual youth as an example. Int J Equity Health. 2016;15(1):1-8. https://doi.org/10.1186/s12939-016-0371-3.

22. IBM. (2020). Downloading IBM SPSS Statistics 26. Retrieved from https:// www.ibm.com/support/pages/downloading-ibm-spss-statistics-26

23. Ifatunji MA, Harnois CE. An explanation for the gender gap in perceptions of discrimination among African Americans. Soc Race Ethnicity. 2016;2(3): 263-88. https://doi.org/10.1177/2332649215613532.

24. Joseph J, Kuo BCH. Black Canadians' coping responses to racial discrimination. J Black Psychol. 2009;35(1):78-101. https://doi.org/10.1177/ 0095798408323384.

25. Kennedy S, Kidd MP, McDonald JT, Biddle N. The healthy immigrant effect: patterns and evidence from four countries. J Int Migr Integr. 2015;16(2):31732. https://doi.org/10.1007/s12134-014-0340-x.

26. Kogan SM, Yu T, Allen KA, Brody GH. Racial microstressors, racial self concept and depressive symptoms among male African Americans during the transition to adulthood. Journal of Youth and Adolescence. 2015;44(4): 898-909. https://doi.org/10.1007/s10964-014-0199-3.

27. Krieger N. Discrimination and health inequities. Int J Health Serv. 2014;44(4): 643-710. https://doi.org/10.2190/HS.44.4.b.
28. Litchmore RVH, Safdar S, O'Doherty K. Ethnic and racial self-identifications of second-generation Canadians of African and Caribbean heritage: an analysis of discourse. J Black Psychol. 2015;42(3):259-92. https://doi.org/10.1177/ 0095798414568454.

29. McCreary Centre Society. (2018). About the BC Adolescent Health Survey. Retrieved from https://mcs.bc.ca/about_bcahs

30. McLaughlin KA, Hatzenbuehler ML, Keyes KM. Responses to discrimination and psychiatric disorders among black, hispanic, female, and lesbian, gay, and bisexual individuals. Am J Public Health. 2010;100(8):1477-84. https:// doi.org/10.2105/AJPH.2009.181586.

31. McNeil Smith S, Sun R, Gordon MS. Racial discrimination and psychological distress among African American adolescents: investigating the social support deterioration model. J Child Fam Stud. 2019;28(6):1613-22. https:// doi.org/10.1007/s10826-019-01397-6.

32. Newman L, Baum F, Javanparast S, O'Rourke K, Carlon L. Addressing social determinants of health inequities through settings: a rapid review. Health Promotion International, 30(suppl 2), ii126-ii143. 2015. https://doi.org/10.1 093/heapro/dav054.

33. O'keefe VM, Wingate L, Cole AB, Hollingsworth DW, Tucker RP. Racial microaggressions lead to suicidal ideation by way of depressive symptoms. Suicide Lfe Threaten Behav. 2015;45(5):567-76. https://doi.org/10.1111/ sltb.12150.

34. Pachter LM, Caldwell CH, Jackson JS, Bernstein BA. Discrimination and mental health in a representative sample of African-American and afroCaribbean youth. J Racial Ethn Health Disparities. 2018;5(4):831-7. https:// doi.org/10.1007/s40615-017-0428-z.

35. Paradies Y, Ben J, Denson N, Elias A, Priest N, Pieterse A, et al. Racism as a determinant of health: a systematic review and meta-analysis. PLoS One. 2015;10(9):1-48. https://doi.org/10.1371/journal.pone.0138511.

36. Pascoe EA, Richman LS. Perceived discrimination and health: a meta analytic review. Psychol Bull. 2009;135(4):531-54. https://doi.org/10.1037/a0016059.

37. Philbrick AM, Wicks CM, Harris IM, Shaft GM, Van Vooren JS. Make refugee health care great [again]. Am J Public Health. 2017;107(5):656-8. https://doi. org/10.2105/A.JPH.2017.303740.

38. Phillips-Beck W, Eni R, Lavoie JG, Kinew KA, Achan GK, Katz A. Confronting racism within the Canadian healthcare system: systemic exclusion of first nations from quality and consistent care. Int J Environ Res Public Health. 2020;17(22):1-20. https://doi.org/10.3390/ijerph17228343.

39. Pottie K, Dahal G, Georgiades K, Premji K, Hassan G. Do first generation immigrant adolescents face higher rates of bullying, violence and suicidal Behaviours than do third generation and native born? J Immigr Minor Health. 2015;17(5):1557-66. https://doi.org/10.1007/s10903-014-0108-6.

40. Priest N, Paradies Y, Trenerry B, Truong M, Karlsen S, Kelly Y. A systematic review of studies examining the relationship between reported racism and health and wellbeing for children and young people. Soc Sci Med. 2013;95: 115-27. https://doi.org/10.1016/j.socscimed.2012.11.031.

41. Priest N, Perry R, Ferdinand A, Kelaher M, Paradies Y. Effects over time of self-reported direct and vicarious racial discrimination on depressive symptoms and loneliness among Australian school students. BMC Psychiatry. 2017;17(1):1-11. https://doi.org/10.1186/s12888-017-1216-3.

42. Richardson BL, Macon TA, Mustafaa FN, Bogan ED, Cole-Lewis Y, Chavous TM. Associations of racial discrimination and parental discrimination coping messages with African American adolescent racial identity. J Youth Adolesc. 2015;44(6):1301-17. https://doi.org/10.1007/s10964-014-0196-6.

43. Saewyc EM, Taylor D, Homma Y, Ogilvie G. Trends in sexual health and risk behaviours among adolescent students in British Columbia. Can J Hum Sex. 2008;17(1-2):1-13.

44. Sangalang CC, Gee GC. Racial discrimination and depressive symptoms among Cambodian American adolescents: the role of gender. Journal of Community Psychology. 2015;43(4):447-65. https://doi.org/10.1002/jcop.21 696.

45. Schmitt MT, Postmes T, Branscombe NR, Garcia A. The consequences of perceived discrimination for psychological well-being: a meta-analytic review. Psychol Bull. 2014;140(4):921-48. https://doi.org/10.1037/a0035754.

46. Shaffer, C. S., Adjei, J., Viljoen, J. L., Douglas, K. S., \& Saewyc, E. M. (2018). Tenyear trends in physical dating violence victimization among adolescent boys and girls in British Columbia, Canada. J Interpersonal Violence doi: https://doi.org/10.1177/0886260518788367, 088626051878836.

47. Singh G, Rodriguez-Lainz A, Kogan MD. Immigrant health inequities in the United States: Use of Eight major national data systems. S World J. Retrieved from. 2013:21. https://doi.org/10.1155/2013/512313. 
48. Sirin SR, Rogers-Sirin L, Cressen J, Gupta T, Ahmed SF. Discrimination-related stress effects on the development of internalizing symptoms among Latino adolescents. Child Dev. 2015;86(3):709-25.

49. Smith, A., Forsyth, K., Poon, C., Peled, M., Saewyc, E., A., \& Society, M. C. (2019). Balance and connection in BC: the health and well-being of our youth. Vancouver, British Columbia. Retrieved from https://www.mcs.bc.ca/ pdf/balance_and_connection.pdf

50. Statistics Canada. (2019). Diversity of the Black population in Canada: An overview. Retrieved from https://www150.statcan.gc.ca/n1/pub/89-657-x/89657-x2019002-eng.htm\#a20

51. Stone AL, Carlisle SK. Racial bullying and adolescent substance use: an examination of school-attending young adolescents in the United States. J Ethn Subst Abus. 2017;16(1):23-42. https://doi.org/10.1080/15332640.2015.1 095666.

52. Szaflarski M, Bauldry S. The effects of perceived discrimination on immigrant and refugee physical and mental health. Adv Med Sociol. 2019;19:173-204. https://doi.org/10.1108/S1057-629020190000019009.

53. Taylor D, Richards D. Triple jeopardy: complexities of racism, sexism, and ageism on the experiences of mental health stigma among Young Canadian black women of Caribbean descent. Front Sociol. 2019;4(May):110. https://doi.org/10.3389/fsoc.2019.00043.

54. Trent M, Dooley DG, Dougé J, Trent ME, Cavanaugh RM, Lacroix AE, et al. The impact of racism on child and adolescent health. Pediatrics. 2019;144(2): e20191765. https://doi.org/10.1542/peds.2019-1765.

55. Umaña-Taylor AJ, Quintana SM, Lee RM, Cross WE, Rivas-Drake D, Schwartz SJ, et al. Ethnic and racial identity during adolescence and into Young adulthood: an integrated conceptualization. Child Dev. 2014;85(1):21-39. https://doi.org/10.1111/cdev.12196.

56. Veenstra G, Patterson AC. Black-white health inequalities in Canada. J Immigr Minor Health. 2016;18(1):51-7. https://doi.org/10.1007/s10903-0140140-6.

57. Viner RM, Ozer EM, Denny S, Marmot M, Resnick M, Fatusi A, et al. Adolescence and the social determinants of health. Lancet. 2012;379(9826): 1641-52. https://doi.org/10.1016/S0140-6736(12)60149-4.

58. Volpe W, Lee DB, Hoggard LS, Rahal D. Racial discrimination and acute physiological responses among black Young adults: the role of racial identity. J Adolesc Health. 2019;64(2):179-85. https://doi.org/10.1016/j.ja dohealth.2018.09.004.

59. Wallace S, Nazroo J, Bécares L. Cumulative effect of racial discrimination on the mental health of ethnic minorities in the United Kingdom. Am J Public Health. 2016;106(7):1294-300. https://doi.org/10.2105/AJPH.2016.303121.

60. Williams DR, Mohammed SA. Racism and health I: pathways and scientific evidence. Am Behav Sci. 2013;57(8):1152-73. https://doi.org/10.1177/0002 764213487340.

61. Zuvekas SH, Fleishman JA. Self-rated mental health and racial/ethnic disparities in mental health service use. Med Care. 2008;46(9):915-23. https://doi.org/10.1097/MLR.0b013e31817919e5.

\section{Publisher's Note}

Springer Nature remains neutral with regard to jurisdictional claims in published maps and institutional affiliations.

Ready to submit your research? Choose BMC and benefit from:

- fast, convenient online submission

- thorough peer review by experienced researchers in your field

- rapid publication on acceptance

- support for research data, including large and complex data types

- gold Open Access which fosters wider collaboration and increased citations

- maximum visibility for your research: over $100 \mathrm{M}$ website views per year

At BMC, research is always in progress.

Learn more biomedcentral.com/submissions 